\title{
DE CÓMO DON DIEGUILLO, INDIO CUECHALE, VIVIÓ DOS VIDAS, LA PROPIA Y LA QUE LE COLGARON
}

\author{
POR
}

CARLOS MANUEL VALDÉS

Universidad Autónoma de Coahuila

Don Dieguillo, indio cuechale que vivió a finales del siglo XVII y principios del XVIII, pasó de colaborador de los españoles a ser acusado de destruir una misión. Finalmente, la captura de otros indios con enseres pertenecientes al establecimiento evangélico demostró la falsedad de los cargos, pero el suceso sirve para analizar las relaciones entre las autoridades civiles y religiosas, locales y lejanas, y los indígenas norteños.

Palabras clave: Misiones, indios, violencia, relaciones inter-étnicas, Septentrión Novohispano.

Don Diego de Valdés, que primero se llamó Dieguillo, indio rebelde a la Real Corona, ya en edad provecta e incapaz de tensar un arco, hubo de ocultarse cuando se enteró que el virrey de la Nueva España, duque de Linares, había ordenado al gobernador de la provincia de la Nueva Extremadura «que muerto o vivo le llevasen la cabeza de dicho don Diego y las demás cabezas de sus parciales $\rangle^{1}$. Las razones para tomar tan extremada decisión, muy rara en la documentación colonial, parecían más que justificadas: Ese caudillo asoló no sólo esa provincia, sino que se le conocieron incursiones en la Nueva Vizcaya por haber atacado la villa del Saltillo y el real de Mapimí, así como pueblos y misiones del Nuevo Reino de León. Todos lo conocían y de todos era temido porque, aun cuando él mismo no tenía la posibilidad de atacar a algunos espa-

1 Expediente formado a consecuencia de la destrucción total de las misiones de Nadadores y San Buenaventura por los Yndios tripas blancas comandados por Diego Valdés, capitán de las Naciones de Oriente, 7 de enero de 1718, Archivo General del Estado de Coahuila, Ramos Arizpe (AGEC), Colonial, caja 2, exp. 10. 
ñoles por la distancia en que se encontraban, lo hacía por medio de subalternos, entre éstos, sus sobrinos Pablo Muñós, llamado el Negrillo, y Nicolás, alias el Carretero, además de el Ronquillo, que fue quien dirigió el ataque nada menos que al presidio de Mapimí, en el que murieron el capitán y sus soldados.

Lo que parece haber sacudido las conciencias españolas y obligado al gobernante a tan grave decisión fue, sin duda, el ataque sistemático a varias misiones que destrozaron o incendiaron, luego de robarles los vasos sagrados, los ornamentos sacerdotales y un misal. El expediente recoge las opiniones de un buen número de vecinos españoles de la villa de Santiago de la Monclova y expresa de manera muy clara la imagen que tiene la población de ese peligroso indio. Las opiniones, pasadas al documento por el escribano, detallan un perfil grandioso del villano despiadado.

Un testigo afirma «que este Don Diego es y a sido de los yndios mas astutos que se an conosido desde Montesuma acá». Otro, bajo juramento, como el anterior, declara que «es y a sido de los yndios mas belicosos y astutos que se an experimentado de ochenta años a esta parte». Un tercero considera que él y sus secuaces dejaron en cueros a unos frailes, añadiendo que,

dieron en un rancho cercano al Presidio del Norte, donde se llevaron toda la caballada. Y saliendo una escuadra de soldados de dho Presidio en su alcance, encontraron con quinse yndios que se volvían en busca de mas caballada, y dando el declarante (que hiva de cavo de dha escuadra de soldados) sobre ellos mataron nueve cojiendo a uno bivo, escapándose los otros cinco que benian; y preguntandole al dho yndio que cojieron bivo que motivos tenian para salir a robar y hacer las maldades que estavan haziendo, a que respondio que por orden de su Capitán Genl Don Diego havian salido de sus misiones a robar caballadas y matar gente.

Uno más, afirma que «Don Diego de Baldés, se ha ejercitado en cometer crueldades induciendo a las demás naciones de la liga prosiguiesen en lo mismo, como también que es de los indios más belicosos e industriosos que se han conocido en las Indias ${ }^{2}$. Sus nombrados sobrinos dejan, asimismo, un rastro de desolación y sangre en diferentes y muy distantes lugares unos de otros. En Monterrey se asientan las maldades de Nicolás el Carretero, que don Diego nombró entre sus parientes. A primera vista se advierte que ese indio es, además de inteligente, atrevido. Inventa un hecho milagroso para atraer a los crédulos españoles, sabiendo que las apariciones son un anzuelo que los atrapa. Al escribano no se le escapó el hecho, pues «sabe que el dicho yndio Carretero se quiere retirar por yr a lograr a los presos que tiene de los españoles que son muchos y que tienen determinado paraxe donde asen sus juntas contra los es-

\footnotetext{
${ }^{2}$ Idem.
} 
pañoles que disfrazan la dicha convocación con benir a desir se les aparece la birgen para coxer alli los españoles: y de una bes matarlos» $»^{3}$.

Tales inventos quedaron grabados en el texto que escribió el capitán Alonso de León: Relación y discursos del descubrimiento, población y pacificación de este Nuevo Reino de León, que abarca hasta el año de $1649^{4}$ y que luego fue continuado por el italiano Juan Bautista Chapa, que había llegado a la Nueva España en 1647. Escribano de varios alcaldes y gobernantes, Chapa nombró su memoria «Historia del Nuevo Reino de León de 1650 a 1690». El interesante escrito seguía la crónica de De León y, al igual que su modelo, tampoco vio la luz en su momento. En esa memoria aparecen, entre muchas otras cuestiones, los ardides de los indios mencionados y de muchos más. Menciona al temible Juanillo el Cuauguijo, recordando que,

poniéndose dicho indio, aquella noche, a platicar con el dicho capitán Alonso de León, interrumpió en muchas quimeras, diciendo que en su tierra se les aparecía la Virgen Santísima y Nuestro Señor, y que les decían que llegaran los españoles de tres en tres a verlos; y que al dicho capitán lo llevarían a ver a Dios y se sentaría a su lado (ficciones que previno la astucia y maldad de dicho indio) ${ }^{5}$.

La idea no era del todo ingenua y resultó atractiva, tanto que se retoma en diversos manuscritos. Puede verse que es un dato del mayor interés: perspicaces indios fabricando una aparición de la Virgen María a sabiendas de que esa devoción figura como elemento fundamental en la fe de un cristiano. Además, el mismo miedo que experimentan los españoles por los ataques indios asegurará su culto, como de hecho sucedió. Notemos que, en el segundo documento, añaden a Cristo entre los aparecidos para atraer a incautos al sitio donde tiene lugar la hierofanía, y ahí matarlos por sorpresa. De hecho, se dice que el $\mathrm{Ca}$ rretero tiene muchos cautivos en los alrededores del sitio de las apariciones.

Lo que resulta más fantástico que el dato mismo es que el autor de la estratagema lleva dos nombres diferentes. En un primer momento se llama Nicolás y es sobrino de nuestro don Dieguillo, y en el que sigue fue bautizado como Juanillo, de la etnia cuauijos. Algo más, el manuscrito que se conserva en

3 Expediente en que constan las disposiciones que se dieron para tranquilizar las naciones de indios de guerra, Archivo Municipal de Monterrey, Monterrey (AMM), ramo Civil, legajo 5 , exp. 47 , f. $2 \mathrm{v}$.

4 Alonso de León entregó su manuscrito para la publicación; incluía la portadilla y la dedicatoria, lo que hace suponer que estaba seguro de que sería impreso. No se sabe por qué nunca lo fue.

5 Chapa, 1980: 160-161. Este escrito se había publicado como anónimo en 1909. En la reedición que cito ya aparece el nombre del autor. Cavazos Garza, 1988, no deja dudas de que se trata de Chapa. 
Monterrey fue redactado por Juan Bautista Chapa, escribano del Cabildo en donde estampó su firma; la segunda la escribe el cronista Juan Bautista Chapa, la misma persona. Empiezan las dificultades en lo que toca a datos y coherencia. No paran ahí las contradicciones porque Chapa, páginas atrás, en su manuscrito, informaba que un grupo de soldados españoles había incursionado más allá del río Bravo o Grande para atacar a la etnia cacaxtle. Conociendo el peligro al que se exponían, imploraron a un indio que estaba asentado de paz en la villa del Saltillo, llamado don Nicolás el Carretero, «juntase gente de su devoción para dar ayuda a los españoles; y juntó trescientos y tantos indios de nación boboles los más» ${ }^{6}$, con cuyo apoyo mataron a cien indios y tomaron setenta como esclavos. De manera que Chapa presenta variaciones sobre un personaje y un evento.

Imaginación e imaginario fueron moneda corriente en la era colonial española en el Septentrión Novohispano. Jean Marie Le Clézio presenta varios casos en que indios de esa enorme región de la Nueva España fabrican hechos maravillosos adaptándolos a las enseñanzas de los religiosos para, al final, retomar el terreno perdido o para crear espacios que, siendo españoles por el contenido, eran indios por sus fines. De ahí que, precisamente los indios más cercanos a las estrategias reales, sean, finalmente, los que la combatirán con mayores posibilidades de éxito ${ }^{7}$.

Sin duda, nuestro cronista, cuya buena pluma es ostensible y su relato histórico, qué es lo que afirma que escribe, ¿olvida o confunde datos? Es difícil establecer que sus confusiones hayan sido intencionales, sin embargo ésas no son las únicas, como veremos. Un escritor bien formado, como lo muestran sus citas de autores clásicos o contemporáneos, además de buen traductor, no deja de inquietarnos por sus olvidos o contradicciones. Si es el Carretero quien persuade a los boboles de apoyar a los españoles y combatir a una etnia que vive tan lejos de ellos, y que es dudoso que tenga conflictos con su propia gente, no se explica cómo un aliado tan importante aparezca luego entre los «perversos enemigos de ambas magestades». Por tanto, el apoyo que dio a la Corona fue real e inestimable. Esto se evidencia porque los boboles eran una

6 Chapa, 1980: 148.

7 Le Clézio, 1988: 198. «La révolte des Indiens du Nayarit, au début du XVIIe siècle, est guidée par un "apostat" du nom de Don Alonso de Leon et les Tepehuanes se regroupent autour d'un Indien Tarahumara qui se fait appeler "roi" sous le nom de Juan Cocle, et prêche la destruction des missions. En 1644, la confédération des "sept nations" (Tobosos, Cabezas, Salineros, Mamites, Julimes, Conchos, Colorados) est inspirée par un cacique Toboso apostat, Geronimo Moranta. La révolte des Tarahumaras en 1646 est guidée par Teporaca, que le père Alegre appelle Indio ladino (converti), et celle des Indiens voisins de Monterrey par un autre ladino nommé Nicolas el Carretero (le Charretier).» 
etnia que vivía en los alrededores del río donde se fundó Santiago de la Monclova, a la sazón capital de la Nueva Extremadura, mientras que, por su parte, los cacaxtles situaban su territorio a centenares de kilómetros de allí. En el río Monclova, sede de Nicolás, juntaba sus aguas el río Nadadores, donde vivía don Diego. Cuando se había fundado Monclova, en 1676, los boboles habían sido los primeros en recibir el bautismo y asimilarse.

¿Por qué los españoles atacaron a los cacaxtles? No queda claro, pero éstos fueron ultimados veinticuatro leguas adelante del Río Bravo, que a su vez se encuentra a doscientos veinte kilómetros del Nadadores ${ }^{8}$. Hay una razón que se disfraza, que se esconde entre líneas, pero que brota si uno conoce la historia del actual Noreste mexicano. Chapa hizo el recuento: «Se mataron cien indios y cogieron setenta piezas entre chicos y grandes » ${ }^{9}$. Un dato más entre los centenares que hemos recogido de la presencia española en esta región que fue, desde su nacimiento, concebida como una reserva de esclavos. La venta clandestina de indios a Las Antillas fue iniciada por el presidente de la Audiencia en 1527, y es la más perversa de las prácticas que desplegaron los europeos en la conquista y colonización de la Nueva España. Insertar en este ambiente a don Diego parece inevitable; hay que regresar en el tiempo para tener una idea de la coyuntura histórica de la que surgió él y las maldades con que lo caracterizaron.

La villa de Santiago del Saltillo se dio por fundada en $1575^{10}$, pero, aun cuando no se cuente con documento específico ni acta de fundación, ahora sabemos que ya existía en $1573^{11}$, como aparece en el listado que publicó Francisco de Solano. Su creador, Alberto del Canto, de origen portugués, también fundó, en 1577, Ojos de Santa Lucía, que sería abandonada casi de inmediato a causa de los ataques de los indios. Ahí mismo se crearía Monterrey en 1596. Este portugués había instituido una villa de españoles en 1577 bajo el nombre de Almadén a doscientos kilómetros al norte de Saltillo, que fue, sin duda, la población que más fundaciones tuvo y más veces fue abandonada (se cuentan nueve) hasta su establecimiento definitivo bajo el nombre de Santiago de la Monclova, en honor del virrey de este título nobiliario, un siglo más tarde, en 1676. La historia de estas tres villas es imprescindible para comprender el pa-

8 Estamos recogiendo un ataque a una etnia que vivía a unos 370 kilómetros de Monterrey, que es el lugar donde se toma la decisión de atacarlos. Tenían una buena razón para una expedición tan onerosa.

9 Chapa, 1980: 148.

10 Siempre se ha tenido como año de fundación 1575, que es el que Alessio Robles, 1934: 47, acepta.

11 Solano, 1990: 55. 
sado regional. Cada una pertenecía a un reino o provincia diferente: a la Nueva Vizcaya la primera, al Nuevo Reino de León la segunda y a la Nueva Extremadura la tercera.

La última fundación de Monclova se realizó a cien años de la de Saltillo y a ochenta de la de Monterrey, lo cual es anormal pero explicable. Los europeos que erigieron Saltillo y Monterrey eran esclavistas. A sus fundadores, Alberto del Canto, Luis de Carvajal y Andrés Montemayor, se les instruyó un juicio por esa actividad. Los motivos del fracaso de Monclova son dos: el primero, el saqueo de piezas para su venta y, el segundo, la capacidad de resistencia de los indios de esa región y sus tradiciones guerreras como cazadores-recolectores $^{12}$.

Desde el siglo XVI se habían realizado entradas en lo que es hoy el Noreste de México, sobre todo en el nombrado Seno Mexicano, para tomar esclavos. Tenemos envíos de indios a Cuba, Santo Domingo y Honduras desde 1527. El primer obispo y arzobispo de México, fray Juan de Zumárraga, denuncia para 1529 el saqueo de quince mil ${ }^{13}$. Pero cuando fueron desapareciendo los aborígenes de la costa, que eran aquéllos a los que más fácilmente y con menos costo podían embarcar rumbo a las Antillas, sus perseguidores ingresaron tierra adentro. Hay una denuncia al rey por secuestro de indígenas del interior en 1564 en el actual territorio de Coahuila, a unos quinientos cincuenta kilómetros del Golfo de México ${ }^{14}$. Con este marco de referencia, no es difícil explicar por qué, desde el principio, el encuentro entre europeos y aborígenes fue no sólo tenso, sino de extrema violencia. De ahí que la primera fundación de una misión por los hijos de San Francisco en el río Nadadores haya dejado por saldo un fraile asesinado en el temprano año de 1607. La muerte de fray Martín de Altamira sería vengada por Francisco de Urdiñola, entonces alcalde de Saltillo y poco después gobernador de la Nueva Vizcaya, acompañado por Diego de Montemayor, alcalde mayor de Monterrey. Los indios camocuanes lo habían asesinado a orillas del río Nadadores, que es la misión en la que nacería don Dieguillo ${ }^{15}$.

Tras los muchos fracasos hispanos para colonizar la región, finalmente logra sobrevivir un pequeño grupo de mineros que establecen una relación de convivencia con los aborígenes. El obispo de Guadalajara, en el informe de su visita pastoral al Rey, se muestra admirado de la labor del cura secular, pagado

12 Valdés, 2006.

13 Zavala, 1994: 28.

14 El registro más antiguo que tengo está en Cartas al Rey, Archivo General de Indias, Sevilla (AGI), Audiencia de México, legajo 1564.

15 AGI, Audiencia de Guadalajara, legajo 66, exp. 6, f. 17. 
por el cabildo de la diócesis. Pide que se le pague congrua, «pues con él no solo se conseguiria el bien espiritual de los ya convertidos, sino tanbien el de muchos gentiles del Río Nadadores [...] las Sabinas [...] y los del Río Bravo» ${ }^{16}$. Pero el sitio todavía no era considerado villa sino un real de minas habitado por pocos habitantes (gambusinos y mineros). Este cura diocesano desarrollaba su labor fenomenal en un radio no menor a los trescientos kilómetros hacia el norte y doscientos al oeste.

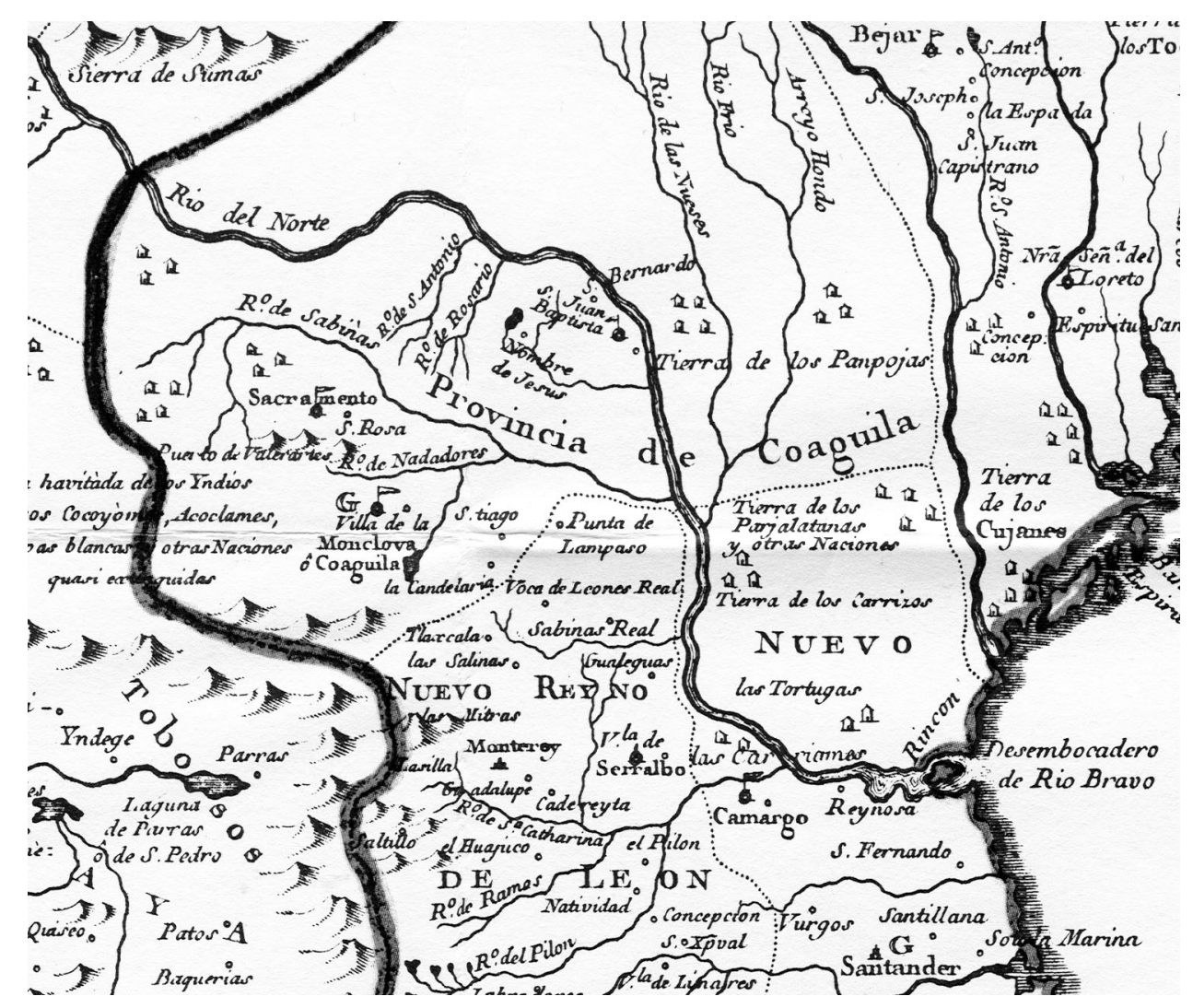

Fragmento del Nuevo Mapa Geográfico de la América Septentrional. José Antonio de Alzate. París, 1768.

16 Informe al Rey de la Visita Pastoral de Juan Ruiz Colmenares, obispo de Guadalajara, 20 de abril de 1649, AGI, Guadalajara, legajo 56. 
El acto fundacional ya no de una villa, sino de la provincia o reino de Nueva Extremadura, no tendrá lugar hasta 1676. Se nombró al mismo tiempo un gobernador de la provincia, un alcalde mayor y varios misioneros franciscanos con territorio e indios comarcanos. Muy pronto, los frailes lograron convencer a ocho adolescentes boboles, hijos de los indios principales, para ir a Guadalajara, donde serían catequizados en una larga estancia en el convento. Estos aborígenes llamaron la atención de la gente por sus costumbres y su indumentaria, su casi desnudez. Regresaron a Monclova al año ya vestidos, bautizados y con nombre y apellido españoles, que a cada uno dio su padrino. Comenzaba la metamorfosis.

No estamos seguros de que el padre de Dieguillo haya sido parte de esta primera cosecha, pero, si no fue así, es claro que estuvo entre los primeros conversos de la nueva misión, pues, además de ser cristiano, sabía leer y escribir, cosa por demás infrecuente en el Septentrión. Por sus dos nombres y apellidos (Juan Francisco Ruiz de Birbiesca) parecería que sí formó parte de los primitivos cristianos formados en Guadalajara. Escribió a su hijo Diego una breve carta desde la hacienda de San Lorenzo, en Parras, donde trabajaba para un empresario agrícola que producía vino y harina de trigo; él se encargaba de conseguir mano de obra para levantar la cosecha entre los indígenas del río Nadadores y su entorno ${ }^{17}$. Como puede verse $-\mathrm{y}$ es algo frecuente entre los indígenas - trocó su nombre y adoptó el de un español.

Este hombre, indio cuechale, también menciona a su nieto, hijo de don Diego, con el que le envía determinados obsequios, lo que nos revela que las relaciones familiares eran cariñosas. Además de ser un enganchador, es decir, alguien que conseguía mano de obra para un español, a su vez menciona que tiene un campo sembrado de trigo y un viñedo, lo que es muy interesante, porque muestra a un indio nómada que dio el paso hacia la sedentarización con todo lo que ésta denota. El indio cuechale produce trigo y vino, enviándole a su hijo Dieguillo un guaje (recipiente natural para conservar líquidos) con aguardiente.

Recordemos aquí que el violento decreto del virrey pidiendo le hagan llegar a la ciudad de México la cabeza de don Diego se da cuando las autoridades de la Nueva Extremadura le informaron que ese malvado indio había saqueado y quemado una misión. Mas, la carta de su padre, se inicia con la frase: «Ha[n]

17 Testimonio de cartas e informes sobre los Presidios del Reino de la Nueva Vizcaya, AGI, Guadalajara, legajo 67-4, II. Publicadas en Hackett, 1926. Aparecen dos cartas, la primera de don Juan Francisco Ruiz de Birbiesca a su hijo Diego de Valdez, San Lorenzo, 18 de mayo de 1692; la segunda de Simón de Echavarria a Don Diego Cuechale, Parras, 18 de mayo de 1692. 
sido para mi de muchisimo gusto y contento las noticias que me das de tu salud, y particularmente la de que fundas Una Mission de Yndios nuevos lo qual te ha de pagar Dios como lo veras y asimismo me hallo muy gozoso de que te lleves y Sirvas a los Padres Ministros de esse Pueblo lo qual te suplico mucho lo hagas siempre pues estos son verdaderos Sacerdottes de Cristiano ${ }^{18}$. Tenemos a un don Diego amenazado porque destruyó una misión en la versión de los habitantes españoles de Monclova. Y tenemos al mismo personaje como creador de una misión. Algo anda mal; los sucesos no concuerdan.

Primero que nada hay un padre piadoso; luego un hijo que recibió el nombramiento de gobernador del pueblo indio de Santa Rosa de los Nadadores, enviado por el propio virrey, cosa nada usual y que significa que ha rendido invaluables servicios al rey. Los nombres del padre e hijo son cristianos y esto también indica algo. Son numerosos los indígenas que, no teniendo nombre de algún santo, adoptaban apodos, como Poco, Periquillo, Tuerto, Ronquillo, Tecolote o Dieguillo. Los apellidos del padre no necesariamente se perpetuaban en los hijos, como es el caso ${ }^{19}$. La segunda carta que aparece en el expediente sevillano nombra cuechale a don Diego, de ahí que esa denominación étnica me parezca la más segura para nuestro personaje, porque se la atribuye su padrino, quizá de bautismo, lo que despeja dudas. Los cuechales, cotzales, quetzales y otras variaciones que anotaban los españoles según fonetizaban lo que creían escuchar, eran una etnia regional dividida en bandas (los manuscritos las llaman parcialidades o naciones), emparentada con los temidos indios del desierto: los tobosos, chizos, cabezas, conianes, contotores y muchos más ${ }^{20}$. Las dos cartas son una curiosa muestra de indios que se han integrado a la economía mercantil, pero que conservan su libertad y no necesariamente han dado la espalda a sus comunidades étnicas.

¿Cuándo aparece don Diego como tal? La primera vez, cuando el obispo de Guadalajara, Santiago de León y Garabito, llega en su visita pastoral a las regiones más apartadas de su enorme diócesis. Al llegar a Monterrey se encuentra con graves problemas, en especial un trato inhumano hacia los indígenas y la respuesta de éstos en forma de ataques a villas, pueblos y viajeros; o, incluso, la práctica de la homosexualidad para no procrear hijos y no darlos como esclavos a los españoles. El maltrato a los indios era tan brutal que el obispo, para tener datos fehacientes, realizó una encuesta entre los pobladores

18 Idem.

19 Cosa que también se encuentra entre los tlaxcaltecas que migraron al Septentrión. Hijos de mismo padre y madre tomaban el apellido paterno el primero, el materno el segundo o el de sus padrinos los siguientes. No he encontrado regla lógica en ello.

20 Griffen, 1969; Valdés, 1995. 
de Monterrey, llamándolos y juramentándolos con su mano en la santa cruz uno a uno. Los resultados de su inteligente investigación le hicieron estallar de ira y se conservan en un larguísimo documento que rescata el ultraje sistemático a que eran sometidos los indígenas. Tan fuerte fue su reacción que excomulgó al gobernador del Nuevo Reino de León, que no sólo no impedía la injusticia, sino que propiciaba el sistema de sometimiento brutal de los nómadas. Después escribió cartas llenas de denuncias al rey, significándole su enojo por la perversidad de los españoles en la región ${ }^{21}$. El monarca, a su vez, exigirá al virrey, con rapidez, el esclarecimiento de las denuncias; éste, por su parte, transmitirá las órdenes al gobernador del Nuevo Reino de León.

Tan grave parece la situación que, temiendo que asalten al obispo en el camino a Saltillo, le ofrecen soldados para acompañarle. A su llegada a Saltillo, Santiago de León y Garabito se encontrará con algunos indios que le buscan ansiosos. El secretario diocesano anota que acaban de llegar a esa villa para verle,

Don Estevan llamado el Gueyquesale, governador de la nacion quesale $=$ Gregorio de la nacion manos prietas, Temastian de los indios de la mision de Santa Rosa de los Nadadores $=$ Matheo de nacion quesale $=$ Agustin de nacion manos prietas $=$ Geronimo de nacion quesale $=$ Diego de nacion assimesmo quesale, todos indios Chichimecos vecinos del Pueblo y Mision de Santa Rosa de los Nadadores en la provincia de Coahuilan llamada la nueba estremadura ${ }^{22}$.

Documento que, de entrada, enumera una comisión de notables de un pueblo indio a los que encabeza el gobernador, acompañado del temastián y otros. Es preciso notar que estos dos añaden a su nombre cristiano un adjetivo náhuatl. Estevan se dice Gueyquesale. En la lengua mexica huey denota a un principal, un jefe: él es el gran quesale. Su segundo es denominado temastián, que es el que, en una misión, hace de catequista, maestro de capilla, fiscal y, en ocasiones, cantor. Los demás son, sin duda, los integrantes del cabildo indio. El único cuyo nombre está precedido del título don, que nada más un gobernador puede portar, es don Estevan ${ }^{23}$. El último nombrado es Diego, aún sin el titular don, que luego lo distinguirá, demostrando que ya fue electo gobernador. Pero a Diego le sigue el nombre quesale, que designa a su etnia ${ }^{24}$.

21 Mexican Manuscripts, 167, Bancroft Collection, University of Berkeley. Cfr Valdés, 1995: cap. 4.

22 Visita al Obispo Juan de Santiago de León y Garabito de unos indios chichimecos, 18 de febrero de 1682, Centro Cultural Vito Alessio Robles, Saltillo (CECUVAR). Manuscritos, tomo I, XII, ff. 16-19.

23 Aclaro que muy pocos españoles de Saltillo o Monterrey pudieron decir su nombre antecedido del apelativo Don al menos en los siglos XVI y XVII.

${ }^{24}$ Los nahuatlismos llaman la atención. Ignoro su procedencia. Pueden haber sido induci- 
Lo que esos indios declararon debió ser traducido por intérprete, indicando con ello que don Estevan no hablaba castellano (muy al contrario de don Diego, cuyo padre e hijo también habían sido alfabetizados). El secretario anotó que venían a señalar,

como todos los religiosos misioneros de las quatro misiones questan en la dicha provincia de Coahuilan se avian convocado y estaban ya juntos y congregados en el Pueblo y mision de San francisco de Coahuilan en la dicha provincia para salirse y desamparar las dichas misiones para lo qual avian juntado todos los ornamentos y su ropa y que requiriendo a dichos padres misioneros el Capitan Protector de dicha misión de Santa Rosa de los Nadadores a que no desamparasen dichas misiones hasta dar quenta de ello a quien se devia y que en caso de salirse y desamparar los dichos Padres misioneros las dichas missiones fuese con toda paz y quietud sin inquietar ni alborotar los indios sino con mucha paz y sosiego, los dichos Religiosos misioneros se havian disgustado con el dho Capitan Protector y assi que los dichos indios chichimecos venian a dar quenta a su Señoria Ilustrisima de que si los dichos Padres missioneros se salian y desamparaban las dichas missiones era por su gusto y no porque los indios les hubieran dado motivo o causa para ello ni hecho a los dichos Religiosos misioneros ninguna vexacion o agravio porque todos estaban muy gustosos, y assi se anticipan a dar esta noticia a su Ilustrísima para que en caso que los dichos misioneros se salgan y desamparen las dichas missiones, no digan que fue por causa de haber recibido de los dichos indios chichimecos alguna vexacion o agravio; y habiendolos su Illma. oido y entendido, les respondio y dixo que se vayan consolados y quietos y respeten mucho a los padres misioneros y no se desconsuelen aunque los dichos Religiosos misioneros se salgan y desamparen las dichas missiones, sino que en caso de hacerlo den quenta con toda brevedad a Su Ilustrísima en la parte y lugar donde se hallare para que luego les remita y envie ministros para que les administren los Santos Sacramentos a los dichos indios chichi$\operatorname{mecos} . .25$.

El repetitivo testimonio no sorprendió a León y Garabito. En su recorrido por el reino de León acababa de constatar que varios religiosos descuidaban a sus catecúmenos y encontró a uno que incluso se prestaba para entregarlos a los perversos encomenderos. Y tal cosa no era novedad en la región, pues el anterior obispo, Ruiz Colmenares, ya citado, señalaba al rey que había quitado a varios frailes el permiso de confesar por ser muy ignorantes. Denunciaba, asimismo, a otros que lo engañaban, diciendo que tenían una misión y no ha-

dos por los tlaxcaltecas que acompañaron a los primeros frailes. Agustín de Vetancurt, franciscano, quien deja entender que estuvo presente, dice que en 1676 los religiosos encontraron «indios de lengua mexicana, aunque tosca» en las misiones del río Nadadores. Vetancurt, 1871: 376-77. Pero el gran experto nahuatlato, Luis Reyes García, en comunicación personal, me dijo que la lengua nahua no tenía ni la más mínima relación con la coahuileña.

25 Visita al Obispo Juan de Santiago de León y Garabito de unos indios chichimecos, 18 de febrero de 1682, Centro Cultural Vito Alessio Robles, Saltillo (CECUVAR). Manuscritos, tomo I, XII, ff. 16-19. 
bía tal, pues la conformaban unos cuantos indios que, por lo demás, eran sus sirvientes. Así que León y Garabito, que pasó por ahí años más tarde, se encolerizó por la situación de violencia. Ahora, ya en Saltillo y para no escandalizar a estos chichimecos, los tranquilizó, prometiéndoles que, si continuaban sus problemas con los frailes, les enviaría sacerdotes diocesanos para suplirlos.

Lo que interesa a nuestro tema es lo siguiente. Para que quede testimonio, el obispo les ruega «parezcan y declaren (lo que tienen declarado ante su Illustrissima) ante el Señor General Don Diego de Valdés, Alcalde Mayor y Capitan a Guerra de esta dicha Villa ${ }^{26}$. Es éste, sin duda, el momento en que Dieguillo adoptará el apellido del alcalde mayor, que, por serlo de la población más grande de la región, debe haber causado en él una impresión profunda. En adelante, lo encontraremos bajo el nombre don Diego de Valdés, y en varios documentos se añadirá: "Capitán de las más de las Naciones de Oriente». La pregunta pertinente ahora es el significado de ese oriente que califica a las sociedades étnicas. Se le menciona así en Monterrey, por lo que podría suponerse que es un indicador concreto porque Monclova y Nadadores están al oeste de esa ciudad. Pero hay que añadir que la referencia nos conduce a las bandas de indígenas situadas entre el pequeño río Nadadores y la enorme región desértica que linda entre los actuales Coahuila y Chihuahua, desierto que sobrepasa con mucho la superficie de Bélgica.

Don Dieguillo resulta, por tanto, un dirigente indio de gran capacidad. De él, contrariamente a don Estevan, podemos asegurar que hablaba y escribía español, lo que duplicaba su capacidad relacional y su dominio de múltiples ambientes. Sabemos también que tenía un conocimiento de los espacios, rutas, ranchos y haciendas. Su propio padre vivía lejos de la tierra natal, junto a $\mathrm{Pa}$ rras, a unos doscientos veinte kilómetros, pero por su carta se entiende que Dieguillo conoce el lugar. Señalan su presencia en Monterrey alentando indios (a ciento treinta kilómetros de su tierra natal). Lo encontramos también en El Saltillo (a doscientos kilómetros del Nadadores) frente al obispo ${ }^{27}$.

Ahora veamos al otro don Diego, el que no sólo no es un forajido al que haya que separarle el cuerpo de la cabeza para llevársela a un virrey demasiado impetuoso, manipulable y extremista junto a las de Nicolás el Carretero y los otros. Don Dieguillo fue un elemento tan importante para la vida de los re-

26 Idem.

27 En un pequeño ensayo se muestra la movilidad que tenían los nómadas, aun los ya hispanizados, como era el caso de Gerónimo Camargo, que conocía grandes extensiones de territorio con los nombres de cada propietario, sabía quién era quién en cada lugar y se expresaba perfectamente en español, náhuatl y coahuileño. Valdés y Corona, 2001. 
ligiosos y para la concordia regional que el virrey (anterior al que pedía su cabeza) le había enviado desde la ciudad de México el nombramiento de gobernador del pueblo indio de Santa Rosa de los Nadadores junto con la vara de mando, cosa pocas veces vista. Sabemos que se trataba de una distinción realmente excepcional. La vara de mando era, en sí misma, una señal de autoridad de tal dimensión que había quien la robaba en un intento de confundir continente y contenido ${ }^{28}$.

También sabemos que Dieguillo ya era muy viejo en 1714, cuando se les ocurrió cortarle la cabeza, por lo que podríamos asegurar que sería un jovencito cuando tuvo lugar la segunda fundación de la misión de Santa Rosa de los Nadadores en 1676. Por los datos etnográficos localizados en los archivos consta que en algunas misiones, las que bordeaban las lagunas, había muchos viejos, algunos incluso centenarios, aunque también sabemos que en ciertas regiones de hábitats del desierto u oasis la gente no envejecía, debido, sobre todo, a los periodos de hambruna que pasaban en temporadas invernales. Para el hábitat del Nadadores no hay datos claros. Uno de los testigos llamados a declarar por el alcalde de Monclova contra nuestro hombre afirmaba en 1714: «Y qe dize el dho Don Diego que aunque aora no le srivan las manos, con la lengua le basta para executar sus maldades. Y que dho Don Diego solo con su vos y Nombre tiene sujetas a todas las naciones barbaras de estas Provincias» ${ }^{29}$.

¿Cuál puede ser el delito tan enorme de don Dieguillo como para sentenciarlo a la pena capital? Lo que molesta a las autoridades de la Nueva Extremadura es que el sujeto sea un apóstata, sacrílego, ladrón, secuestrador y asesino. En efecto, ¿no fue él quien robó en la misión de Santa Rosa de los Nadadores?, ¿acaso no tomó el cáliz sagrado, las crismeras, la patena y demás alhajas del templo?, ¿no despojó a los pobres franciscanos de sus ornamentos litúrgicos?, ¿tampoco capturó la caballada? Apresarlo, enjuiciarlo, dictarle pena de muerte, cortarle la cabeza... no es más que buscar el equilibrio. Ninguno de los españoles cuyo testimonio recoge el expediente titubeó al poner al servicio de la justicia la información que recordaba las muchas maldades de don Diego de Valdés.

28 Hoy en día todavía se utilizan las varas de mando en muchas comunidades indígenas, como los yaquis, los tarahumaras, los tepehuanos, los mixtecos y los tzotziles. Y nada más un cobanao (cabeza principal) o gobernador puede portarla.

29 Expediente formado a consecuencia de la destrucción total de las misiones de Nadadores y San Buenaventura por los Yndios tripas blancas comandados por Diego Valdés, capitán de las Naciones de Oriente, 7 de enero de 1718, Archivo General del Estado de Coahuila, Ramos Arizpe (AGEC), Colonial, caja 2, exp. 10. 
El expediente judicial no tiene fallas. Contiene la información suficiente para llevar al criminal al patíbulo. Pero sucedió algo que nadie hubiera esperado. Muy lejos, a poco más de setecientos kilómetros, no lejos del Parral, capital de la Nueva Vizcaya, el capitán Juan de Retana, enviado por el gobernador de la Nueva Vizcaya para reprimir a grupos indios que atacaban las caravanas, se topa con un grupo que huye a un monte muy alto. Lo acompaña un don Nicolás, gobernador, que puede ser El Carretero, pero no consta. Retana deja escrito: «Zerque dicho Peñol e el rededor asi de soldados Como de Yndios Amigos y hecho esto procure asaltar dicho Peñon por tres ó quatro veces peleando hasta las quatro de la tarde lo qual no se pudo conseguir por la aspereza de la mucha peñasqueria a pie ni a cavallo haviendo salido a estas horas quatro soldados heridos con diez Yndios amigos y uno muerto» ${ }^{30}$. Al fin logran ingresar los «Yndios Amigos» y matan a veintidós varones y ocho mujeres. En el lugar encuentran los cadáveres, así como a un niño que había sido secuestrado en la misión de Nadadores y, lo más increíble, «Se Vido y Reconocio aver algunas alaxas de Iglesia como es un Misal; Estola y Manipulo Campanilla y hostiario y Alba despedazada Con ottras Carttas y papeles que segun parece Son de alguna Mission de Cuaguila Con un titulo de Gobernador en Don Diego De Valdez dado por el Excelentisimo Señor Conde de Galve Virrey de la Nueva España Y también unas cartas y Patentes del Ministro de la Mission que parece asolaron los enemigos» ${ }^{31}$.

El documento es asombroso. Indios nómadas que, cuando robaban una misión o una hacienda, tomaban todo lo que pudiera ser comido, sobre todo el maíz, aunque también se llevaban los caballos y algunos bovinos para comerlos luego. Pero aquí tomaron los ornamentos sacerdotales y los vasos sagrados. ¿Para qué querrían tal cosa y por qué transportarlas cientos de kilómetros? No parece haber más explicación que la de considerar esos objetos como insignias, elementos propiciatorios, mágicos, protectores. No es la primera vez que indios nómadas roban vestiduras sacerdotales y las portan, imitando las ceremonias rituales cristianas. Aún más, los hubo que se designaron obispos y bautizaron y confesaron a sus compañeros.

La sociedad tribal que atacó Nadadores era designada por el nombre de chizos, que tenían su asiento en la confluencia de los ríos Concho y Bravo (pegada al actual territorio de los Estados Unidos). Su radio de acción era de, al menos, setecientos kilómetros. Pero en Nadadores no nada más robaron a los

30 Testimonio de cartas e informes sobre los presidios del reino de la Nueva Vizcaya, AGI, Guadalajara, legajo 67-4, II.

31 Idem. 
frailes, también se llevaron los bueyes de don Diego ${ }^{32}$. Un elemento importante surgió de esa casualidad, pues desde la Nueva Vizcaya se informa al virrey que «Don Diego Valdez Yndio Governador de los Naturales de el Pueblo de Cuaguila de la Nacion nombrada de los Nadadores por si y por lo que toca a dichos naturales como mas aya lugar digo que dichos naturales se hallan oprimidos de algunos españoles ${ }^{33}$. Pero las sorpresas no terminan porque el manuscrito advierte al virrey que quien ha vejado y robado a don Diego es el mismo gobernador de la Nueva Extremadura, Alonso de León. Pero éste ya había adelantado informaciones a manera de coartada. Anotó su escribano que,

luego que llegué a este dicho pueblo se me dio noticia de cómo los yndios revelados, llamados los colorados, contotores y connianes y otras nasiones como acostumbrados y embisiados en aser daños, muertes y rovos, asi en los viandantes y pasajeros [...] y prosiguieron sus ynsultos ysieron junta y dieron en la mision de Contotores pegando fuego a las seldas donde los religiosos se avian guarecido con la demas jente yrieron a uno de estos religiosos de un arcabusazo y mataron un yndio de dicha mision dejando a otros mal eridos, llevandose los ornamentos, calis, y patena y las cabras que tenian en dicha mision, obligando a despoblarse y la mision de Nadadores retirandose los misioneros a este pueblo de temor de los enemigos, todo lo qual es publico y notorio ${ }^{34}$.

Se conserva en Texas un documento firmado por él que dice su opinión también. ¿Cuál es la razón para que veinte años más tarde, después que Juan de Retana encontró las alhajas de la misión de Nadadores, se acuse falsamente a don Diego, ya viejo, de aquello, como si acabase de suceder? La respuesta parece sencilla. El nuevo gobernador de la Nueva Extremadura sabe que una misión sin indios pierde, de inmediato, su razón de ser. Amedrentado y oculto don Diego, los indígenas huirán (como lo hicieron) y no quedará a los frailes más que abandonar la misión (como sucedió). Una vez la misión sin habitantes y el pueblo indio desperdigado, el gobernador declarará baldío el territorio misional y podrá hacer merced de las tierras a españoles (como lo hace). Mas lo

32 Huerta Preciado, 1966: 97. «También para fines del siglo XVII, surgió un nuevo peligro en el Reino de la Nueva Vizcaya, a las diversas naciones indígenas ya conocidas, se agregaron otras tantas procedentes del río del Norte, que poco a poco se introdujeron y mezclaron con las antiguas; se mencionan particularmente a los chizos, que se convirtieron en un serio peligro para el Reino de la Nueva Vizcaya; estos indios solían congregarse en la Junta de los ríos Conchos y del Norte y ya se les podía considerar los más perniciosos de la Nueva Vizcaya».

33 Testimonio de cartas e informes sobre los presidios del reino de la Nueva Vizcaya, AGI, Guadalajara, legajo 67-4, II.

34 Tamez Tejeda, 1996: 38. Autos de Guerra fechos por mi, el General Alosno de León Gobernador y Capitán del presidio de esta provincia de Coahuila, 1683. El autor presenta y paleografía este manuscrito que se encuentra en la University of Texas at Austin, The Nettie Lee Benson Collection, WBS 2053. 
inesperado da con la clave del suceso: el hijo del gobernador recibe las tierras como merced real. Aclaremos que no se trata de terrenos cualesquiera, pues tienen edificios, sistema de riego con acequias, bordos y tierras ya desbrozadas para el cultivo y sitios para criar ganado. Todo resultó en beneficio de un gobernante corrupto. La perversa imagen de don Diego, creada en todas sus piezas, era nada más que un pretexto. Sin él, ningún obstáculo se opondría a sus designios. Y así sucedió.

El conocimiento de la documentación enseña cuán difícil es comprender el pasado. En este caso se creó a un delincuente y se fomentó un imaginario coherente, creíble en la ciudad de México y en Madrid. Sólo que no habían calculado que un capitán que pasó casi inadvertido, encontraría las pruebas de que don Diego de Valdés, o Dieguillo, indio cuechale, no sólo no merecía la pena de muerte, sino el agradecimiento por ser un indio anómalo en esa región tan alejada de los poderes reales. Entre fábulas, chismes e intereses se fraguó la historia de don Diego. Una historia a la medida.

\section{BIBLIOGRAFÍA}

Alessio Robles, Vito, Saltillo en la historia y en la leyenda, México, A. del Bosque, 1934.

Alonso de León, «Relación y discursos del descubrimiento, población y pacificación de este Nuevo Reino de León», en Historia de Nuevo León con noticias sobre Coahuila, Tamaulipas, Texas y Nuevo México, Monterrey, Ayuntamiento de Monterrey, 1980: 1-119. Estudio preliminar y notas de Israel Cavazos Garza.

Cavazos Garza, Israel, El cronista anónimo, Monterrey, AGENL, 1988.

Chapa, Juan Bautista, «Historia del Nuevo Reino de León de 1650 a 1690», Israel Cavazos Garza (ed.), Historia de Nuevo León con noticias sobre Coahuila, Tamaulipas, Texas y Nuevo México, Monterrey, Ayuntamiento de Monterrey, 1980: 121-226.

Griffen, William B., Culture Change and Shifting Populations in Central Northern Mexico, Tucson, The University of Arizona Press, 1969.

Hackett, Charles Wilson (ed.), Historical Documents Relating to New Mexico, Nueva Vizcaya, and Approaches Thereto, to 1773, Washington, Carnegie Institution, 1926. Documentos escogidos, anotados y paleografiados por Adolph y Fanny Bandelier.

Hoyo, Eugenio del, Indios, frailes y encomenderos en el Nuevo Reino de León. Siglos XVII y XVIII, Monterrey, Archivo General del Estado de Nuevo León, 1985.

Huerta Preciado, María Teresa, Rebeliones indígenas en el Noreste de México en la época colonial, México, Instituto Nacional de Antropología e Historia, 1966.

Le Clézio, J.M.G., Le rêve mexicain ou la pensée interrompue, Paris, Gallimard, 1988. 
Montemayor Hernández, Andrés, La congrega. Nuevo Reino de León. Siglos XVI-XVIII, Monterrey, Archivo General del Estado de Nuevo León, 1990.

Solano, Francisco de, Ciudades hispanoamericanas y pueblos de indios, Madrid, Consejo Superior de Investigaciones Científicas, 1990.

Tamez Tejeda, Antonio, Cimientos de lo nuestro, Monterrey, Universidad de Monterrey, 1996.

Valdés, Carlos Manuel, La gente del mezquite. Los nómadas del noreste en la Colonia, México, CIESAS e INI, 1995.

Valdés, Carlos Manuel, «Umbrales del Noreste Mexicano actual», Isabel Ortega Ridaura (coord.), El Noreste. Reflexiones, Monterrey, Fondo Editorial de Nuevo León, 2006: 21-31.

Valdés, Carlos Manuel y Sergio Antonio Corona, Gerónimo Camargo indio coahuileño, Torreón, Universidad Iberoamericana e Instituto Municipal de Cultura de Salti1lo, 2001.

Valdés, Carlos Manuel y Sergio Antonio Corona, Ataque a la misión de Nadadores, Torreón, Universidad Iberoamericana, 2002.

Zavala, Silvio, Entradas, congregas y encomiendas en el Nuevo Reino de León, Sevilla, Universidad de Sevilla, 1992.

Zavala, Silvio, Los esclavos indios en Nueva España, México, El Colegio Nacional, 1994.

Recibido el 15 de agosto de 2009

Aprobado el 19 de noviembre de 2009

\section{HOW DON DIEGUILLO, A CUECHALE INDIAN, LIVED TWO LIVES, HIS OWN AND THE ONE THEY LABELLED HIM WITH}

Don Dieguillo, a Cuechale Indian who lived at the end of the $17^{\text {th }}$ century and the beginning of the $18^{\text {th }}$, collaborated with the Spanish, but was accused of destroying a mission. Finally, other Indians were captured with items belonging to the religious establishment, proving the charges to be false. However, the incident serves to analyse the relations between the different authorities (civil and religious, local and remote) and the northern indigenous people.

Key words: Missions, Indians, violence, inter-ethnic relations, Septentrión Novohispano (Northern New Spain). 